\title{
ESL Learners' Interaction in an Online Discussion via Facebook
}

\author{
Halizah Omar ${ }^{1}$, Mohamed Amin Embi ${ }^{1} \&$ Melor Md Yunus ${ }^{1}$ \\ ${ }^{1}$ Faculty of Education, Universiti Kebangsaan Malaysia, Bangi, Malaysia \\ Correspondence: Halizah Omar, Faculty of Education, Universiti Kebangsaan Malaysia, 43600 Bangi, Selangor, \\ Malaysia. Tel: 60-13-208-1008. E-mail: halizahom@gmail.com
}

Received: April 19, 2012 Accepted: May 16, 2012 Online Published: August 17, 2012

doi:10.5539/ass.v8n11p67 URL: http://dx.doi.org/10.5539/ass.v8n11p67

\begin{abstract}
This study aims to investigate ESL learners' participation in an information-sharing task conducted via Facebook (FB) groups and their feedback on the use of FB groups as the platform for the activity. An intact group of 31 learners taking a communication course at a public university participated in the study. Data analysed in this paper were derived from a threaded online discussion and an open-ended questionnaire. Descriptive statistical analysis showed the learners' substantial contribution to the group discussion despite their limited language ability and technical problems. Thematic analysis revealed that the use of FB as a platform for the information-sharing task received very positive feedback from the participants, thus suggesting it would be a promising virtual tool and environment to promote interaction in English learning. More activities using FB groups should be assigned for learners to practice and use communicative language. Promoting awareness of available online tools and modelling effective use of the tools are suggested to help enhance learners' online interactions.
\end{abstract}

Keywords: online discussion, Facebook (FB) groups, social networking tool, language learning, interaction

\section{Introduction}

The proliferating use of social networking tools among youth has prompted educators to incorporate these in a variety of educational endeavours. In institutions of higher learning, learners' heavy reliance on these tools is now common since the tools provide a platform to connect with classmates, course mates, lecturers, and administrators. Despite resistance to and scepticism over the incorporation of these social networking tools for classroom practice, language teachers and lecturers, for instance, have made attempts to explore and utilise these tools to enrich their teaching and assist learners in improving their language learning (Lockyer \& Patterson 2008; Nakatsukasa 2009). Online discussion (OLD) via these tools could help expand learning and knowledge acquisition beyond the four walls of traditional classrooms (Perez 2003; Supyan \& Azhar 2008) by encouraging learners to interact with their peers and lecturers in the target language.

This paper, therefore, attempts to shed light on an information-sharing activity conducted via OLD using FB groups and involving an intact class of tertiary level learners at the National University of Malaysia (UKM). The learners' participation in the task and their feedback on the use of FB groups as the platform for the activity were investigated. Some pedagogical implications and suggestions to further enhance learners' online interactions were also outlined.

\section{Literature Review}

Computer-mediated communication (CMC), defined as 'the exchange of information between individuals by way of computer networks' (Rovai 2007: 78), comprises synchronous (real time) and asynchronous (delayed time) communication. Synchronous CMC, such as instant messaging, chats, and video conferencing, refers to real-time communication that requires user participation at the same time. Asynchronous CMC, on the other hand, refers to delayed written communication, which does not require user participation in real time (Romiszowski \& Mason 2004). Information is transmitted by participants at the pace and time most convenient to them (Hiltz et al. 2007), such as via email or an electronic discussion board.

In the context of Malaysian universities, asynchronous CMC, such as OLD, seems to be more feasible and convenient as its flexible feature enables learner interactions with instructors, classmates, or peers 'anytime and 
anywhere' (Ranjit \& Mohamed Amin 2008; Wu \& Hiltz 2004) without any spatial or time limitations. Despite technical limitations such as network restrictions, bandwidth constraints, or public computer facilities, learners can participate in OLD using their own netbook or laptop since each faculty and residential college has Wi-Fi zones. Online interactions can, therefore, be conducted at a time and place most convenient to learners.

Weisskirch and Milburn (2003: 216) define OLD as an 'electronic forum that allows the user to post a message for others to read and to which others can respond'. These posted messages are accessible at any time and remain visible until they are deleted. Each participant can read and refer to the posted messages as many times as they wish and make necessary amendments or improvements to their own messages before posting them. Unrestricted by space and time, OLD is a 'platform for language instructors to extend learning activities outside classroom' (Supyan \& Azhar 2008: 108), thus providing an additional environment for communicative language use and practice.

Empirical studies revealed numerous benefits of OLD in language classes. These include increased participation among students (Chun 1994; Kern 1995; Masputeriah 2006), improved quality of language outputs (Kern 1995; Warschauer 1996), enriched vocabulary (Perez 2003), a collaborative learning environment (Amelia, Mohamed Amin \& Rosseni 2009; Chun 1994; Ranjit \& Mohamed Amin 2008), learner autonomy (Ranjit 2008), and expansion of learners' Zone of Proximal Development (Supyan 2009). It also provides a more equitable platform and a less threatening environment for second language discussion (Masputeriah 2006; Supyan 2008; Warschauer 1996). OLD, therefore, mainly benefits shy or introvert learners as it allows some privacy in interaction. Additionally, any apprehension in communicating face-to-face and disclosing participants' real identity could be reduced. Hence, apart from acquiring new information and knowledge, those having trouble expressing themselves can also share their views and opinions.

Facebook (FB), synonymous with social media among school and university students, could be described as the most popular social networking tool of this decade. FB has the highest number of visitors among all the social networking tools available in Web 2.0, with more than 840 million active users worldwide (Facebook Statistics 2012). Ranked 17th in the world in terms of FB usage, Malaysia has 12.23 million FB users, which is 72 per cent of the country's online population (Malaysia Facebook Statistics 2012). Studies carried out by Kamaluddeen et al. (2010) and Safurah et al. (2010) showed higher FB usage compared to other social networking tools among their respondents comprising undergraduates in higher learning institutions in Malaysia, with nearly half the number using it daily (Safurah et al. 2010). Their daily usage could possibly have been due to its special features and various social applications (Kamaluddeen et al. 2010), including the discussion board, email, chatting, links, tagging, and the ability to upload and share videos and pictures, which make FB an interesting and promising tool for educational pursuits. Malaysian learners perceived FB as an educational environment that could facilitate English language learning (Kabilan et al. 2010), enhancing language skills and motivation, confidence, and attitudes towards learning the language. The FB platform generates authentic interaction which could boost learners' confidence and collaborative efforts. In view of the increasing number of learners who are also avid FB users, it seems pertinent that this platform be explored and utilised to support language learning.

Considering learners' low competence and limited ESL ability, they usually have trouble articulating their views and opinions. OLD provides an extra avenue for them to practice the language. Engaging these learners in a task that could elicit more productive output should, therefore, be encouraged. Learner interaction on OLD boards supports a learner-centred, socio-constructivist approach to teaching which includes social and collaborative learning processes (Althaus 1997).

Whilst a number of research on learners' asynchronous interactions utilized learning management system (LMS) (e.g Amelia et al. 2009; Berhannudin \& Wan Fara Adlina 2009; Dawson 2006; Ranjit \& Mohamed Amin 2010), this study, on the contrary, selected FB, the most prominent social media of the decade, as a platform for learners' interaction. In addition, despite a growing number of recent studies that have been conducted on the educational use of FB (Buzzetto-More 2012, Melor \& Hadi 2012; Sewlyn 2009; Shih 2011; White 2009), very few, if any, looked into ESL learners' participation in an OLD via FB groups and their perception of the use of FB groups in task-based activities. The findings of the study, therefore, will give an insight into learners' participation in and perceptions of the FB group in an information-sharing task, as well their implications to language teaching and learning.

\section{Methodology}

Using a case study approach, this paper aims to investigate how an intact group of 31 learners taking a communication course at the National University of Malaysia participated in an information-sharing task, an evaluated component. A maximum score of 15 per cent was awarded for the task. The goal of the task was to 
engage learners in sharing and exchanging views in groups of four or five members on general or academic topics and themes selected by the learners and the course instructor. The information-sharing task required each group to select one of three shortlisted topics for discussion: natural disasters (ND), strange festivals (SF), and weird diseases (WD). The 31 students were divided into four groups of four and three groups of five members. Three groups chose ND, while the other two topics were covered by two groups each.

The participants had differing levels of English proficiency and belonged to different course disciplines. A majority (80.6 per cent) were learners of Malaysian University English Test (MUET), Band Three or lower, categorised as modest, limited and extremely limited users of English. They were undergraduates from the Faculty of Education, Faculty of Science \& Technology, and Faculty of Business \& Economics.

Each group was represented by learners of mixed proficiency levels to facilitate the discussion. Within three weeks of initiating discussion on the topic, participants were required to post a minimum of six substantial entries, including a summary of the selected article, questions, and responses to questions asked by their group members. The assistant instructor-cum-researcher moderated the OLD. This included giving a briefing on how the task was to be conducted, inviting learners to FB discussion groups, responding to any enquiries regarding the task, and, at times, encouraging lurkers to participate in a more in-depth discussion. This study considers and counts only substantial learner-to-learner entries that contain meaningful responses related to the issues discussed.

Data analysed for this paper was gathered from the threaded OLD of the information-sharing task via FB groups and an open-ended questionnaire on the participants' opinions on the use of FB groups in the task. Of the 31 participants, 28 (90.3 per cent) responded to the questionnaire. Descriptive statistical analysis was undertaken to obtain the frequency count and mean for posted messages across the groups and for the whole class. Responses on the open-ended questionnaire were categorised according to emerging themes.

\section{Findings \& Discussion}

\subsection{Learners' Participation in the OLD via FB Groups}

Descriptive statistical analysis of the threaded discussions among participants revealed the learners' rather active contributions in the discussion. This was corroborated by the number of substantial entries or posted messages by group members. The seven groups in the OLD together posted 559 substantial messages as part of the information-sharing task (Table 1). The groups and participants completed the task with varying contributions. Generating the highest number of entries, totalling 147 (26.3\%), SF5 was considered the most active group with a mean of 29.4 entries per group member. This was followed by ND2 and SF4 with a mean of 19.25 and 17.5, respectively. Among group members, participant number three of SF5 (SF5:P3) generated the highest number of entries (42), while participant number two of ND1 (ND1:P2) produced the lowest (10). The findings also revealed that the average number of entries for each group member was 18, that is, three times more than the task requirement.

Table 1. Group-wise entries in the information-sharing task via FB

\begin{tabular}{|c|c|c|c|c|c|c|c|c|}
\hline $\begin{array}{l}\text { Group no./ } \\
\text { Participant }\end{array}$ & P1 & P2 & P3 & P4 & P5 & $\begin{array}{l}\text { Total no. of group } \\
\text { entries }\end{array}$ & $\%$ & $\begin{array}{c}\text { Mean of entries per } \\
\text { group }\end{array}$ \\
\hline ND1 & 11 & 10 & 11 & 13 & - & 45 & 8.05 & 11.25 \\
\hline ND 2 & 15 & 15 & 18 & 29 & - & 77 & 13.77 & 19.25 \\
\hline ND3 & 23 & 11 & 14 & 13 & - & 61 & 10.91 & 15.25 \\
\hline SF 4 & 21 & 21 & 15 & 13 & - & 70 & 12.52 & 17.50 \\
\hline SF 5 & 33 & 13 & 42 & 25 & 34 & 147 & 26.29 & 29.40 \\
\hline WD 6 & 14 & 16 & 22 & 12 & 20 & 84 & 15.02 & 16.80 \\
\hline WD 7 & 13 & 16 & 15 & 16 & 15 & 75 & 13.40 & 15.00 \\
\hline \multicolumn{6}{|c|}{ Total no. of entries } & 559 & 100.00 & 18.03 \\
\hline
\end{tabular}

A summary of an SF article posted by participant number three of SF5 (SF5:P3) received 47 comments, the highest number of responses among all group members. An example of the threaded discussion is shown in Figure 1. 


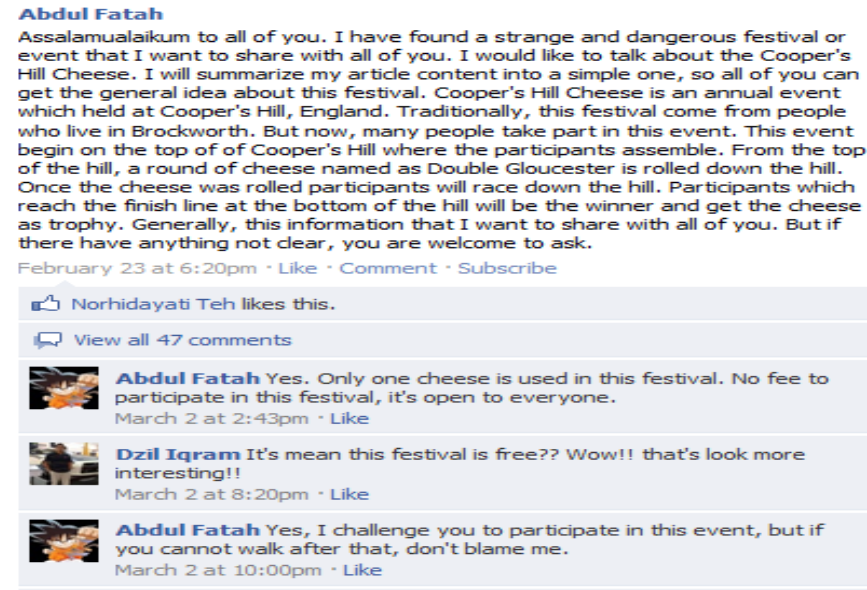

Figure 1. An excerpt of an entry by Strange Festival Group 5 (SF5)

Results indicated that despite having language problems and technical difficulties, these participants were motivated to take an active part in the OLD. This could be due to the attention, immediate responses, and feedback provided by their group members. In fact, they seemed less shy and apprehensive about interacting virtually since their physical presence, which could intimidate or limit their participation, was not required for the task. Hence, participants were able to make a greater contribution by posting a number of messages. In fact, explanations were not only in textual form, but also as pictures, videos, and links on related topics (Figure 2). Apart from making the OLD more interesting, the use of this hypermedia could have facilitated a better understanding of the topic or issue discussed.

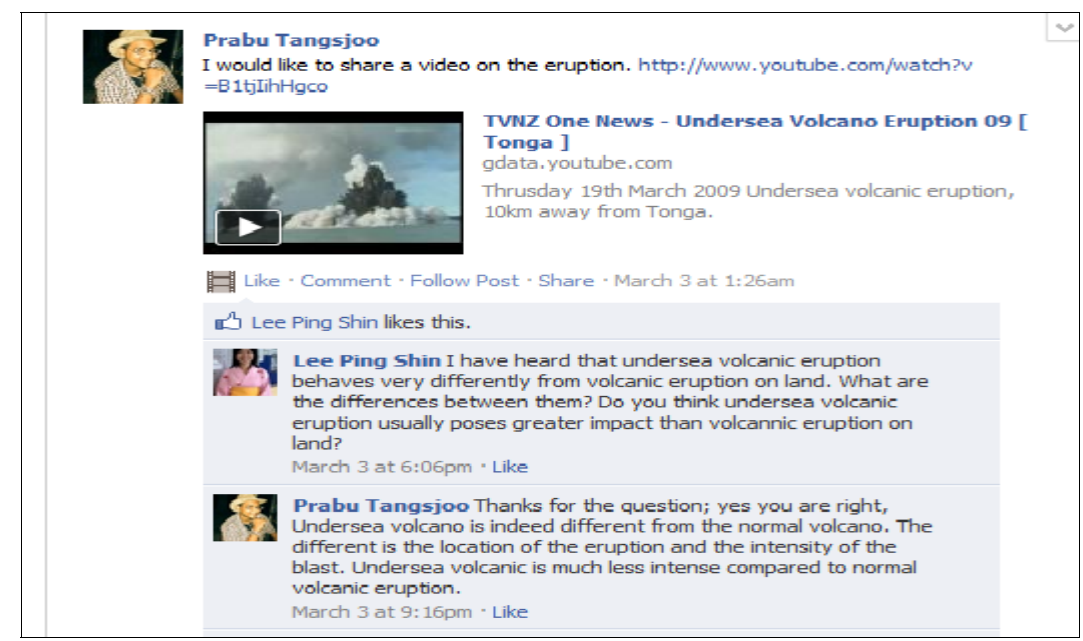

Figure 2. An excerpt of an OLD that includes a participant's (ND1) entry with a video link and comments

The quality of the messages produced was also enhanced as questions and responses were more carefully constructed before posting. To be able to draft informative and meaningful responses, the participants would have had to undertake further reading. They had to have a certain level of understanding of the article and apply critical thinking skills before being able to pose and answer questions in the OLD. The online task seemed to promote knowledge building as learners had to read more, reference, share, and exchange new information with their group members. The task also appeared to facilitate the development of learners' critical thinking as it required them to carefully analyse and synthesise information before posting messages.

Utilising available tools, such as online dictionaries and Google Translate, participants were able to search for more appropriate words to express their opinions and ideas. Problems in constructing sentences were overcome partly because these tools provided some necessary assistance, such as vocabulary, translation, grammar, and spell check. Thus, to some extent, the interactive OLD could have enhanced not only these participants' reading and critical thinking skills but also their vocabulary and grammar. 


\subsection{Learners' Perception of the Use of the OLD via FB Groups in the Information-Sharing Task}

All 28 participants (100\%) who responded to the questionnaire had a favourable perception of the use of FB groups as a platform for their information-sharing task, with the only hindrance being limitations imposed by Internet connections. A closer scrutiny of their responses on the use of FB groups for the OLD revealed four opinions: good (13), useful (6), easy \& convenient (6), and interesting \& enjoyable (3). The following section discusses and illustrates some of the participants' responses regarding the use of FB for their OLD.

\section{Good}

Participants considered the use of FB groups for the OLD a good method since it provided an avenue for them to communicate more freely and comfortably with their group members, especially those who were shy and lacked confidence for face-to-face interaction. For example, one participant (Q12) aptly noted, 'It's a good method to practice our English among friends and lecturers...' whilst participant Q24 wrote, 'I think it must be used in the university. It's good for students who are shy to communicate.' These learners welcomed the opportunity to interact online since it could help them to overcome their shyness and develop their self-confidence.

The absence of restrictions in terms of time and place enabled greater interaction, fostering increased collaboration and a closer relationship with group members. This is evidenced by participant Q20's observation: 'In my opinion it's good... to discuss with group members. We can also be closer to our group members.' Additionally, the participants also believed that the OLD offered a platform to help improve their English, particularly their vocabulary, since they had ample time to think of more appropriate words to express their ideas. This notion is supported by the following comments: 'I think this method is very effective in improving our vocabulary and the information can be delivered effectively' (Q7) and 'It's good because it can improve our English. It gives us some time to think of the answer for the discussion' (Q20). This finding seems to corroborate that of Chun (1994), Warschauer (1996), and Masputeriah (2006): the OLD promotes greater interaction among learners and provides a less stressful environment for less competent learners.

\section{Useful}

Participants found OLD via FB groups useful as it helped with their vocabulary and grammar. The platform facilitated and supported the use of other tools for looking up the meaning of unknown words in either textual or graphical forms, such as Google Translate and online dictionaries. This is evident from the following remarks made by two learners:

'It really helps me because when I don't know some words, I can use the Google Translate. So our information sharing will work smoothly.' (Q25)

'I think it's useful and I can improve my English too. It can also help me to speak or write with good vocabulary and grammar. I can find the words that I want to use in communication.' (Q13)

The participants also felt that OLD was useful especially among those who lacked confidence and were hesitant to participate in face-to-face interactions in English since they seldom used the language. For instance, participant Q27 commented, 'It really helps me to complete the information-sharing task because I'm a person who rarely communicates with people in English. I feel very scared and my confidence level is very low when I'm talking to people in English. So this method really helps me.' In fact, Q28's statement indicated his clear preference for the use of the OLD via FB, 'It helps me a lot and makes me confident to give opinion and share information with others. I love it so much.'

This finding seems to be compatible with that of Ranjit and Mohamed Amin (2008) as well as Supyan (2009): learners perceived OLD as a useful tool to help in their interactions with each other to accomplish the assigned task. Mazman and Usluel's study (2010) on modelling educational usage of FB confirmed 'usefulness' as the main reason for the rapid adoption of FB and the speedy increase in its number of users.

\section{Easy and Convenient}

FB features such as links, video and photo uploading, etc. were utilised by participants to enhance their group interaction. Their regular FB usage possibly lent a degree of comfort to using the application in the discussion. Most importantly, it allowed interactions to take place at their convenience with no time restriction and without having to meet face-to-face. The participants' responses pertaining to this aspect are as shown below:

'I think online discussion using FB is convenient as all facilities like chatting, links, videos, and 
photo-sharing sessions are available in FB for us to attach any additional information.' (Q11)

'As university students, we are always busy with our work; as such, we don't have much time to meet our group members. So, the social network is really convenient. We can interact with each other without the need to meet up.' (Q18)

FB also helps support the use of hypermedia such as pictures, videos, and links to further illustrate, explain, and justify the participants' arguments or opinions, thus enriching the learners' interaction.

\section{Interesting \& Enjoyable}

Having been given the opportunity to carry out an OLD via FB groups, the participants acknowledged that it was interesting and enjoyable. Responses given by two participants testified to this aspect: 'Interesting and this method has helped to improve my communication skills' (Q6) and 'It is interesting and we can spend more time to have an interesting and effective discussion there' (Q8). Although the main reason OLD via FB was considered interesting was not explicitly stated, these comments suggest that the participants believed using an interesting platform could elicit and promote a more interactive discussion, which, in turn, could help enhance their communication skills.

Furthermore, one of the participants (Q15) commented, 'Students enjoy it more than face-to-face discussion. Students nowadays love to use FB.' Another participant (Q2) shared a similar view: 'I feel happy. I think I can improve my language. For example, my friends use some words that I don't know, so I can find the words and learn them.' These positive remarks about the OLD via FB groups suggest the participants' inclination towards virtual interaction as an additional or alternative activity to support traditional classroom language learning.

Despite the positive feedback discussed above, two participants highlighted network problems such as limited Wi-Fi coverage at their residential colleges which caused inconvenience and limited their participation in the discussion. In addition, another participant commented that some group members did not respond to posted messages, making them feel their effort was not worthwhile. One participant also noted his concern that English speaking skills might not improve through virtual interaction.

\section{Conclusion, Implications and Suggestions}

This paper has shed some light on learners' participation in information-sharing activity conducted via FB. In view of the positive feedback from participants, the OLD via FB groups can be regarded as a promising virtual tool and an environment that could promote constructive interaction among ESL learners. It provides an alternative platform that can help support delayed responses in language use and practice. Hence, its incorporation in class activities could boost learners' confidence and collaboration in generating an authentic and more effective discussion. As FB has become a significant part of students' lives, utilising the tool in a pedagogically sound approach could benefit ESL learners in practicing the language outside their classrooms. Research with a larger population sample, and engaging learners in other interactive language activities using FB, would provide additional insights into their participation and contributions. Longer durations for assigned tasks could yield richer data which could provide a more comprehensive understanding of learners' interaction patterns.

Unlike in a traditional classroom, the OLD participants in this study seemed to have taken up a more active role in assigned groups as the teacher's role was decentralised. Fear of the teacher or any member dominating the discussion or disagreeing with their opinions and ideas was minimised due to the absence of verbal or non-verbal cues, which could have impeded participation. Therefore, more tasks and activities could be assigned to elicit an interactive discussion among group members. OLD activities should be given a reasonable weighting in the course so that learners feel that their efforts are worthwhile. As the task can be time consuming, a substantial percentage should be allocated to encourage group members to become active contributors in the discussion. To further encourage learners' participation, the main focus of the task should be on comprehensibility rather than language accuracy. However, once learners have gained confidence in interacting with each other, instructors or moderators might need to highlight learners' common grammatical errors. By doing this, the OLD will be more meaningful to the learners as they would have some guidance on correct language input from instructors or moderators.

As the OLD can help support the use of online tools such as grammar checker, Google Translate, Language Translator, and online dictionaries, instructors could perhaps promote awareness of available tools that could help learners improve their online interaction through writing. Instructors could demonstrate how these tools can be used effectively in the classroom prior to the OLD activities. This is in line with the point made by Blattner 
and Fiori (2009: 18) that educators need to 'guide learners to make use of various e-tools for academic purposes, create a dynamic learning environment, promote critical thinking, authentic second language (L2) learning opportunities'. Learners should, therefore, be encouraged to use these tools before posting their messages in FB groups, in order to help them produce more accurate lexis and sentences.

\section{References}

Althaus, S. (1997). Computer-mediated communication in the university classroom: an experiment with online discussions. Communication Education, 46(3), 158-174. http://dx.doi.org/10.1080/03634529709379088

Amelia Abdullah, Mohamed Amin Embi, \& Rosseni Din. (2009). Development of a collaborative learning community through computer-mediated communication. In Mohamed Amin Embi (Ed.), Computer-Mediated Communication: Pedagogical Implications of Malaysian Research Finding (pp. 112-127). Shah Alam: Karisma Publications Sdn. Bhd.

Berhannudin Mohd Salleh, \& Wan Fara Adlina Wan Mansor. (2009). Speak it out \& be heard online. In Mohamed Amin Embi (Ed.), Computer-Mediated Communication: Pedagogical Implications of Malaysian Research Finding (pp. 112-127). Shah Alam: Karisma Publications Sdn. Bhd.

Blattner, G., \& Fiori, M. (2009). Facebook in the Language Classroom: Promises and Possibilities. International Journal of Instructional Technology and Distance Learning, 6(1), 17-28.

Buzzetto-More, N. (2012). Social networking in undergraduate education. Interdisciplinary Journal of Information, Knowledge \& Management, 7, 63-90.

Chun, D. M. (1994). Using computer networking to facilitate the acquisition of interactive competence. System, 22(1), 17-31. http://dx.doi.org/10.1016/0346-251X(94)90037-X

Dawson, S. (2006). Online forum discussion interactions as an indicator of student community. Australasian Journal of Educational Technology, 22(4), 495-510.

Facebook Statistics. (2012). Retrieved from http://newsroom.fb.com/content/default.aspx?NewsAreaId=22

Hiltz, S. R., Turoff, M., \& Harasim, L. (2007). Development and philosophy of the field of asynchronous learning networks. The SAGE Handbook of E-learning Research. London: SAGE Publications.

Kabilan, M. K., Ahmad, N., \& Zainol Abidin, M. J. (2010). Facebook: An online environment for learning of English in institutions of higher education? Internet and Higher Education, 13(4), 179-187. http://dx.doi.org/10.1016/j.iheduc.2010.07.003

Kamaluddeen Usman Danyaro, Jafreezal Jaafar, Rod Allan A. De Lara, \& Alan G. Downe. (2010). An evaluation of the usage of web 2.0 among tertiary level students in Malaysia. International Symposium on Information Technology 2010 (ITSim 2010). Kuala Lumpur.

Kern, R. (1995). Restructuring classroom interaction with networked computers: Effects on quantity and characteristics of language production. The Modern Language Journal, 79(4), 457-476. http://dx.doi.org/10.1111/j.1540-4781.1995.tb05445.x

Lockyer, L., \& Patterson, J. (2008). Integrating social networking technologies in education: A case study of a formal learning environment. In 8th IEEE International Conference on Advanced Learning Technologies. Retrieved from http://ro.uow.edu.au/cgi/viewcontent.cgi?article=1074\&context=edupapers

Malaysia Facebook Statistics. (2012). Retrieved from http://www.socialbakers.com/facebook-statistics/malaysia

Masputeriah Hamzah. (2006). Use of computer-mediated communication to facilitate second language acquisition. In Muhamad Kamarul Kabilan, Norizan Razak, \& Mohamed Amin Embi (Eds.), Online teaching and Learning in ELT (pp. 159-176). Pulau Pinang: Universiti Sains Malaysia.

Mazman, S. G., \& Usluel, Y. K. (2010). Modeling educational usage of Facebook. Computers \& Education, 55, 444-453. http://dx.doi.org/10.1016/j.compedu.2010.02.008

Melor Md Yunus, \& Hadi Salehi. (2012). The effectiveness of Facebook groups on Teaching and Improving Writing: Students' perceptions. Journal of Education and Information Technologies, 1(6), 87-96.

Nakatsukasa, K. (2009). The efficacy and students' perceptions of collaborative blogging in an ESL classroom. In C. A. Chapelle, H. G. Jun, \& I. Katz (Eds.), Developing and evaluating learning materials (pp. 69-84). Ames, IA: Iowa State University.

Perez, L. C. (2003). Foreign language productivity in synchronous versus asynchronous computer-mediated communication. CALICO Journal, 21(1), 89-104. 
Ranjit Kaur, \& Mohamed Amin Embi. (2008). Async is a synch: What Malaysian adult learners have to say? International Journal of Excellence in e-Learning, 1(2), 1-14.

Ranjit Kaur, \& Mohamed Amin Embi. (2010). Learner e-tivities: Exploring Malaysian learners' roles in asynchronous computer-mediated communication. European Journal of Education Studies, 2(2), 157-174.

Ranjit Kaur. (2008). Learner autonomy through online asynchronous online interactions (AOI). Unpublished PHD Thesis. Universiti Kebangsaan Malaysia.

Romiszowski, A., \& Mason, R. (2004). Computer-mediated communication. In D. H. Jonassen (Ed.), Handbook of research on educational communications and technology (pp. 397-432). Mahwah, New Jersey: Lawrence Erlbaum Inc.

Rovai, A. P. (2007). Facilitating online discussions effectively. Internet and Higher Education, 10, 77-88. http://dx.doi.org/10.1016/j.iheduc.2006.10.001

Safurah Abd Jalil, Khaizuran Abd Jalil, \& Azmi Abdul Latiff. (2010, June). Social Media and our youth today: Exploring the impact of social media on Malaysian youth. International Conference on Communications and Media, Bayview Hotel, Malacca.

Selwyn, N. (2009). Faceworking: exploring students' education-related use of Facebook. Learning, Media and Technology. 34 (2), 157-174. http://dx.doi.org/10.1080/17439880902923622

Shih, R.-C. (2011). Can Web 2.0 technology assist college students in learning English writing? Integrating Facebook and peer assessment with blended learning. Australasian Journal of Educational Technology, 27(Special issue, 5), 829-845.

Supyan Husin, \& Azhar Jaludin. (2008). The prospects of online forum at tertiary level. In Abd. Ghafur, \& Norizan Abdul Razak (Eds.), Policy and implementation of E-learning at institutions of higher learning (pp. 108-122). Bangi: Pusat Pembangunan Akademik UKM.

Supyan Hussin. (2008). Creating a bigger Z.P.D. for ESL learners via online forum in Malaysia. College Teaching Methods \& Styles Journal, 4(11), 1-10.

Supyan Hussin. (2009). Revisiting e-forums in English language teaching \& learning. In Mohamed Amin Embi (Ed.), Computer-mediated communication: Pedagogical implications of Malaysian research findings (pp. 90-111). Shah Alam: Karisma Publications Sdn. Bhd.

Warschauer, M. (1996). Comparing face-to-face and electronic discussion in the second language classroom. CALICO Journal, 13(2), 7-26.

Weisskirch, R. S., \& Milburn, S. S. (2003). Virtual discussion: Understanding college students' electronic bulletin board use. Internet and Higher Education, 6, 215-225. http://dx.doi.org/10.1016/S1096-7516(03)00042-3

White, J. (2009). The use of Facebook to improve motivation and academic writing. Proceedings of the Third International Wireless Ready Symposium, 28-32.

Wu, D., \& Hiltz, S. R. (2004). Predicting learning from asynchronous online discussions. Journal of Asynchronous Learning Networks, 8(2), 139-152. 